\title{
Rapid Assessment and Classification for Seismic Damage of Mountain Tunnel Based on Concentric Circle Method
}

\author{
Hua Xu $\mathbb{D}^{1},{ }^{1}$ Jingsong $X u,{ }^{1,2}$ Runfang Sun, ${ }^{1}$ Hefu $\mathrm{Pu}^{3}$ and Yin Cheng ${ }^{1}$ \\ ${ }^{1}$ Key Laboratory of Transportation Tunnel Engineering, Ministry of Education, School of Civil Engineering, \\ Southwest Jiaotong University, Chengdu 610031, China \\ ${ }^{2}$ Yunnan Communications Investment \& Construction Group CO.LTD, Kunming 650100, China \\ ${ }^{3}$ School of Civil Engineering and Mechanics, Huazhong University of Science and Technology, Wuhan 430074, China \\ Correspondence should be addressed to $\mathrm{Hua} \mathrm{Xu}$; xuhua@swjtu.edu.cn
}

Received 11 March 2021; Accepted 15 May 2021; Published 27 May 2021

Academic Editor: Honglue Qu

Copyright (c) $2021 \mathrm{Hua} \mathrm{Xu}$ et al. This is an open access article distributed under the Creative Commons Attribution License, which permits unrestricted use, distribution, and reproduction in any medium, provided the original work is properly cited.

\begin{abstract}
Concentric circle method (CCM), a new method based on analytic hierarchy process (AHP) and numerical discretization of 40 mountain tunnels damaged by Wenchuan earthquake in China, is proposed to rapidly assess the seismic damage level (SDL) of mountain tunnels. The new method consists of four components. First, according to the type and degree of seismic damage of tunnel, the whole tunnel is divided into a number of successive sections. Second, four factors (i.e., slope and portal damage, lining damage, pavement damage, and earthquake collapse) are selected as the main controlling factor set, and then multilevel factor sets are proposed to establish the assessment system. Third, the discretized assessment indexes and classification criteria are established for the rapid assessment of SDL of mountain tunnel. Finally, based on the comprehensive analysis on the SDL of each section, the SDL of the whole tunnel is calculated in terms of the seismic damage index and synthetic radius. With the assessment results shown on a straightforward concentric circle diagram, the proposed CCM method can rapidly and reliably assess the SDL of mountain tunnel to win over precious time for emergency rescue and provide references for the repair of damaged tunnel. In addition, the accuracy and applicability of the proposed method is verified by using a case study of Longxi tunnel located at the epicenter of the Wenchuan earthquake in China.
\end{abstract}

\section{Introduction}

A significant number of tunnels and underground structures have been damaged during earthquakes. In particular, the mountain tunnels located in high-intensity seismic area are more prone to serious damage because of closing to fracture zone. For example, $16 \%$ of the railway mountain tunnels located within the disaster area were seriously damaged during Hyogoken-Nanbu earthquake occurred in Japan in 1995 [1]; $26 \%$ of the 50 mountain tunnels located within $25 \mathrm{~km}$ of the earthquake fault were severely damaged, and $22 \%$ moderately damaged during the Chi-Chi earthquake occurred in Central Taiwan in 1999 [2]; 65\% of the 40 mountain tunnels near the epicenter were damaged during the Wenchuan earthquake occurred in 2008 in Sichuan, China [3]. In addition, mountain tunnels suffered from extremely severe seismic damage usually blocked the traffic almost entirely, resulting in substantial difficulty in emergency rescue and disaster relief. Therefore, a rapid assessment of seismic damage level (SDL) after earthquake would have significant importance on timely and efficient operation of emergency rescue and remedial measures in mountain tunnels.

Recently, an increasing number of researchers and engineers have carried out field investigation and mechanism analysis on seismic damage of tunnels and underground structures during earthquakes [4-11]. Regarding the current research on the seismic damage assessment, most researchers mainly focused on the identification of risk factors and evaluation of seismic damage of tunnels, but less attentions were paid to the SDL assessment. Wang et al. [2] conducted a systematic statistics and assessment of damage 
in mountain tunnels resulted from the 1999 Taiwan Chi-Chi earthquake and analyzed the potential factors. Using the least square method according to tunnel's traffic function and damage description based on the site investigation, Fang et al. [12] proposed an equation for the evaluation of tunnel seismic damage. Jiang et al. [13] analyzed the tunnel damage caused by the $2004 \mathrm{Mid}$ Niigata Prefecture earthquake using Hayashi's quantification theory type II. Wang et al. [14] proposed a new classification criterion to classify the seismic damage and a risk-based assessment technique to quantify the seismic risk. Zang et al. [15] summarized the main influencing factors and put forward a fuzzy comprehensive evaluation method to study the seismic risk level of tunnel portals. Nevertheless, there are still some shortages so far. For instance, owing to the complex multi-index system, complicated calculations, and single assessment result, these methods stated above are not so simple, resulting in great difficulty in applying the rapid assessment to tunnel seismic damage. Moreover, the assessment methods mentioned above do not take the slope and portal damage into comprehensive consideration. As a result, the crews and vehicles for emergency rescue and disaster relief cannot pass through the damaged tunnels, whose accessibility is not assessed and guaranteed, but have to seek detours, which significantly slows down the emergency rescue.

Therefore, combining analytic hierarchy process (AHP) with numerical discretization, a new method called concentric circle method (CCM) is proposed to allow for rapid assessment of the SDL of mountain tunnels. Although the concept of CCM has been applied in different fields, such as camera calibration [16], the principle of those differs from the CCM in this paper. Besides, the CCM has not been introduced to the seismic damage assessment of mountain tunnels so far. The idea of AHP is to treat the object of interest as a system for deciding online with the way of thinking, viz., decomposition, comparative judgment, and comprehensive analysis $[17,18]$. The idea of the numerical discretization is dividing continuous values into several intervals, using mathematical methods $[19,20]$. Because of the conciseness and practicality, the two methods have been widely applied in various engineering fields, such as risk assessment of tunnel engineering and slope stability classification $[14,21]$.

With the assessment results shown on a straightforward concentric circle diagram, the proposed method can rapidly and accurately assess the SDL of mountain tunnel to win over precious time for emergency rescue and provide references for the repair of damaged tunnel. Moreover, the accuracy and applicability of the proposed method was illustrated using the field data of damaged mountain tunnels in the 2008 Wenchuan earthquake, China.

\section{Statistical Analysis on the Seismic Damage Type of Mountain Tunnels}

Tens of mountain tunnels suffered from some degree of seismic damage during the 2008 Wenchuan earthquake in China. The typical seismic damages in the mountain tunnels include collapse and slide of slope, collapse of lining and surrounding rock, cracks of tunnel portal, cracks and displacement of lining, upheaval and cracks of tunnel invert $[3,9,14,22]$. A field investigation into 11 tunnels on the new Dujiangyan-to-Wenchuan highway found that 8 tunnels located near the epicenter were severely damaged. In particular, the Longxi tunnel suffered from destructive damage, involving extensive large-scale lining cracks, severely distorted steel arch and bar, large-scale lining peeling-off, lining collapse up to tens of meters, significant crack and upheaval as high as $120 \mathrm{~cm}$ from tunnel pavement, and totally five large-scale collapses in the whole tunnel. Thereby, the statistical analyses on field investigation data of 40 damaged mountain tunnels during Wenchuan earthquake $[3,9,14,21]$ have been carried out with regard to the types and degrees of seismic damage of mountain tunnels. The main seismic damage types of mountain tunnels are summarized in Table 1, which may provide a useful reference for establishing the seismic damage assessment system and selecting the appropriate assessment indexes.

The tunnel portal section is generally more prone to seismic damage than the tunnel tube section, because of less confining force from the surrounding rock and larger seismic inertial force. In particular, the tunnel portal slope is prone to severe seismic damage due to the action of seismic surface wave and the ground acceleration amplification effect. The main types of seismic damage at the tunnel portal slope include rock falls, collapse, and landslide, which are likely to damage the portal structure or even block the tunnel portal, significantly hindering the emergency rescue after earthquake. According to the report about statistical analysis of the field investigation data of damaged mountain tunnels in the 2008 Wenchuan earthquake by Highway Planning, Survey, Design, and Research Institute of Sichuan Provincial Department [23], the seismic damage of portal slope and portal structure in the tunnel portal section is the most common type and occurred for $97.18 \%$ of all the seismic damages of this section (Figure 1). Therefore, the damage of portal slope and portal structure should be taken into careful consideration in establishing the assessment and classification system and in selecting assessment indexes.

The seismic damage types and characteristics of tunnel tube are different from those of the tunnel portal due to different influencing factors, the surrounding rock conditions, and seismic inertial force. The mountain tunnels located on two highways (i.e., Dujiangyan-Yingxiu Highway and Dujiangyan-Yingxiu section of National Highway No. 213) near the epicenter suffered from extensive seismic damage during the Wenchuan earthquake. Statistical analyses of the seismic damage types and proportions of the damaged tunnel tube for these two highways showed that the main damage types are lining damages and road pavement damages (Figure 2). The lining damages mainly include cracks (longitudinal, transverse, oblique, and radial), peeling-off, falling, collapsing, water leakage, and shear displacement, and the road pavement damages mainly include upheaval and cracks (longitudinal and transverse). The lining damages greatly reduce the strength and safety of tunnel. For the road pavement damages, the rescue vehicles may not pass through the damaged tunnel, which will 
TABLE 1: Main seismic damage types of mountain tunnels during Wenchuan earthquake.

\begin{tabular}{|c|c|}
\hline Tunnel section & Main damage types \\
\hline Portal & $\begin{array}{c}\text { Slope: mountain chipping, crack, collapse, landslide, rock falls } \\
\text { Portal: crack, tilt, sink, buried, tunnel opencut punctured } \\
\text { Lining: crack, aliquation, peeling-off, falling, collapse, dislocation, water seepage, construction joint crack and dislocation }\end{array}$ \\
\hline Tube & $\begin{array}{c}\text { Lining: crack, aliquation, exfoliating, falling, collapse, dislocation, water seepage, construction joint crack and dislocation } \\
\text { Road or invert: crack, fracture, upheaval } \\
\text { Surrounding rock: collapse } \\
\text { Others: decorative surface drop, groove, and other facility damage }\end{array}$ \\
\hline
\end{tabular}

significantly delay emergency rescue. Therefore, the lining damages and the road pavement damages are typical and severe in the seismic damage of tunnel tube and should be taken into significant consideration in establishing the assessment and classification system and in selecting the assessment indexes.

The collapse of surrounding rock is the most severe damage type among all seismic damages for tunnels. Once happened, it hinders or even completely blocks the rescue vehicles, and also it takes high economic cost and long time to repair the collapsed surrounding rock. In Longxi tunnel during the Wenchuan earthquake, for example, it took tens of millions of RMB and duration of 3 months to repair five locations of the collapsed surrounding rock. It is recommended that the collapse of surrounding rock be given the highest level of seismic damage in the assessment and classification system for tunnels.

Some other seismic damages of tunnel, including dropping of decorative surface layer, road groove damage, accessory equipment damage, and others, are also introduced in Table 1. Because these seismic damages have lesser impact on the safety of tunnel structure and the rescue remedy, they are not taken into consideration in the rapid assessment system.

\section{Rapid Assessment and Classification Based on CCM}

3.1. Assessment and Classification System of Tunnel Seismic Damage. The tunnel is a linear system with certain length, consisting of the tunnel lining structure and surrounding rock. After earthquake, the type and degree of seismic damage are different at various sections of the tunnel due to varying properties of surrounding rock and supporting structure. Therefore, based on the type and degree of seismic damage, the whole tunnel is divided into successive sections with certain length in longitudinal direction $\left(l_{1}, l_{2}, l_{3}, \ldots, l_{n}\right)$ using the numerical discretization, with each section having uniform seismic damage.

The influence of each index on the result can be quantified via a weight, to allow an explicit process. Based on the idea of AHP and statistical analysis on the field investigation data of 40 damaged mountain tunnels during Wenchuan earthquake, four main factors, i.e., the slope and portal damage, the lining damage, the pavement damage, and the earthquake collapse, are selected as the controlling factor sets of level 1 in the rapid assessment and classification system. Each controlling factor set is divided into secondary factor sets, which are then further divided into the next level factor sets. Finally, a set of effective assessment and classification system covering complete multilevel factor sets and specific quantitative parameters is established as shown in Figure 3.

Level-1 factor set: the assessment and classification for seismic damage of the whole tunnel is comprehensive analysis on the SDL of each tunnel section from entrance to exit. According to the type and degree of seismic damage, the damaged tunnel is divided into successive sections with certain length in longitudinal direction so as to establish the level-1factor set as follows:

$$
U=\left\{U_{l 1}, U_{l 2}, U_{l 3}, \ldots, U_{l n}\right\},
$$

where $U$ is the seismic damage of the tunnel as a whole and $U_{i}\left(i=l_{1}, l_{2}, l_{3}, \ldots, l_{n}\right)$ is the seismic damage of the respective tunnel section.

Level-2 factor set: the main seismic damage types at various sections include the portal and slope damage, the lining damage, the road pavement damage, and the earthquake collapse, which have significant effect on the safety of tunnel structure and postearthquake emergency rescue, as described in Section 2. As a result, they are selected as the level-2 factor set as follows:

$$
U_{l i}=\left\{u_{1}, u_{2}, u_{3}, u_{4}\right\},
$$

where $u_{1}, u_{2}, u_{3}$, and $u_{4}$ are the portal and slope damage, the lining damage, the road pavement damage, and the earthquake collapse, respectively.

Level-3 factor set: the main type of portal and slope damage $\left(u_{1}\right)$ includes crack, collapse, landslide and rock falls from slope, crack, and tilt of tunnel portal; the main type of tunnel lining damage $\left(u_{2}\right)$ includes crack, peeling-off, water leakage, and shear displacement; the main type of pavement damage $\left(u_{3}\right)$ include crack and upheaval; earthquake collapse $\left(u_{4}\right)$ is surrounding rock collapse induced by earthquake. Herein, this study only takes the lining damage $\left(u_{2}\right)$ as an example to establish the level- 3 and level-4 factor sets, while other factor sets $\left(u_{1}, u_{3}, u_{4}\right)$ of level 3 and level 4 are shown in Figure 3:

$$
u_{2}=\left\{u_{21}, u_{22}, u_{23}, u_{24}\right\},
$$

where $u_{21}, u_{22}, u_{23}$, and $u_{24}$ are crack, peeling-off, water leakage, and shear displacement, respectively.

Level-4 factor set: it is obvious that different damage types have different characteristics, and thus, in order to reflect the attribute values of different damage types, the 


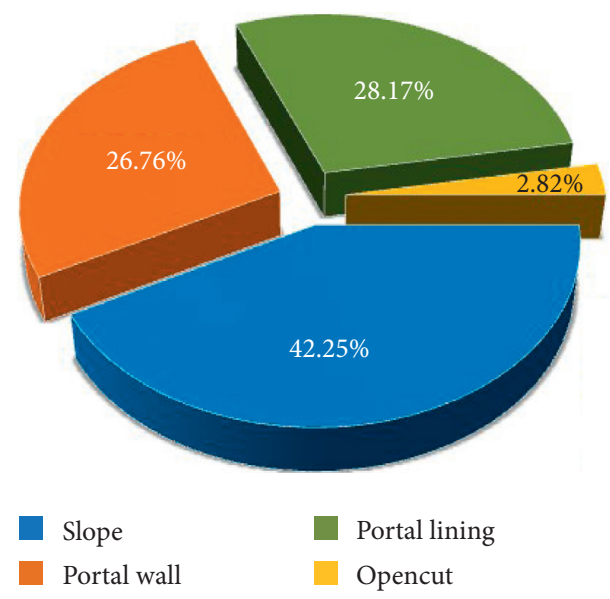

FIgUre 1: Percentage distribution of different seismic damage types in tunnel portal section.

level-4 factor set is established to reflect the degree of the same seismic damage type. For example, $u_{21}$ can be expressed as follows:

$$
u_{21}=\left\{n_{1}, n_{2}, n_{3}, n_{4}\right\},
$$

where $n_{1}, n_{2}, n_{3}$, and $n_{4}$ are the length, width, density, and direction of crack, respectively.

3.2. Development of CCM. The rapid assessment and classification of tunnel seismic damage based on the CCM is carried out according to the following thoughts. First, the seismic damage level (SDL) is discretized and quantified into five levels with the corresponding seismic damage descriptions and discrete values $(0,1,2,3$, and 4$)$, such that the initial CCM diagram is drawn with different radius $(=1,2,3$, and 4). Second, according to the type and degree of seismic damage, the to-be-assessed tunnel is divided into a number of sections with different lengths, and the length is proportionally allocated as an arc in the CCM diagram. Third, the SDL of each section (i.e., the radius in CCM diagram) is calculated according to the parameters of assessment indexes. Finally, based on the comprehensive analysis on the SDL of each section, the SDL of the tunnel as a whole is calculated by the seismic damage index and synthetic radius introduced in later section below, and then the assessment result can be clearly shown on the CCM diagram in a straightforward way. The procedure of establishing the CCM is described in detail as follows:

Step 1: draw the initial CCM diagram.

On the basis of statistical analysis of the data from the field investigation of tunnel seismic damage, the SDL is quantified to 5 levels (i.e., undamaged, slight, moderate, severe, and extremely severe) with their corresponding seismic damage description and discrete value (i.e., 0,1 , 2, 3, and 4) introduced in Section 4.5. As such, the initial CCM diagram is drawn with radius of $1,2,3$, and 4 , with the larger radius representing a greater SDL (Figure 4).
Step 2: divide the whole damaged tunnel into sections. Using discretization, the whole tunnel $(l)$ is divided to $n$ successive sections. The type and degree of seismic damage are almost the same for one section. The length of the $i$ th section is denoted as $l_{i}$, which gives

$$
l=l_{1}+l_{2}+l_{3}+\cdots+l_{i}+\cdots+l_{n},
$$

where $l$ is the total length of the tunnel and $n$ is the total number of the divided sections.

Step 3: allocate the angle and arc of each section.

In the CCM diagram, the linear tunnel is treated as a $360^{\circ}$ circle, so the $i$ th section tunnel can be represented by an angle $\theta_{i}$, where $\theta_{i}$ is the ratio of the length of the $i$ th section to the total length of tunnel (equation (2) and $l_{i}$ is the length of the $i$ th section (not the length of the corresponding arc of $\theta_{i}$ in CCM diagram):

$$
\theta_{i}=\frac{l_{i}}{l} \times 2 \pi, \quad i=1,2,3, \ldots, n,
$$

where $n$ is the total number of tunnel sections.

In this way, we can successively assess and classify the seismic damage of each section using the idea of AHP. Once the sector domain with a specific angle $\theta_{i}$ in the CCM diagram is allocated to the $i$ th section (Figure 5), the contribution of SDL of the $i$ th section to the overall assessment and classification of tunnel seismic damage can be further confirmed. At the beginning of the whole assessment and classification process, the $x$-axis positive half shaft $0^{\circ}$ is treated as the entrance portal of the tunnel. With the increase of counterclockwise angle, the longitudinal assessment for tunnel seismic damage is continuously carried out in the order of sections divided beforehand to the $x$-axis positive half shaft $360^{\circ}$, which is treated as the exit portal of the tunnel. Step 4: determine the radius for the SDL of each section. The radius is determined by the SDL of each section. According to the seismic damage investigation data for the $i$ th section, together with multilevel factor sets and specific quantitative parameters, the radius for the SDL of the $i$ th section is calculated and denoted as $r_{i}$.

To illustrate how to calculate the radius in detail, the $i$ th section of the tunnel is taken as an example. First, it is very important to sort out the field investigation damage data according to the four main seismic damage types and multilevel factor sets. Second, based on the sorted data, the indexes of four main seismic damage types are determinated for the multilevel factor sets of the $i$ th section. As a result, the level of four main seismic damage types is independently assessed as five possible damage levels which, respectively, correspond to five discrete values (i.e., $0,1,2,3$, and 4 ). Finally, due to the independence of four main seismic damage types in the assessment system, the highest damage level among four types should be regarded as the damage level of the $i$ th section and the discrete value corresponding to the highest damage level is then adopted as 


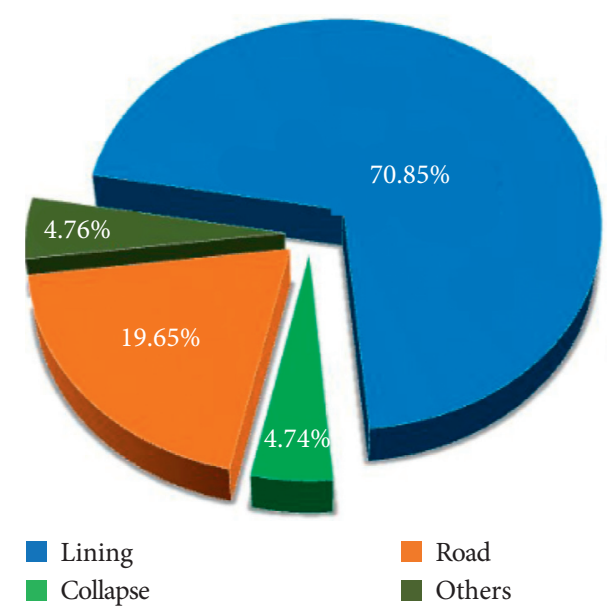

(a)

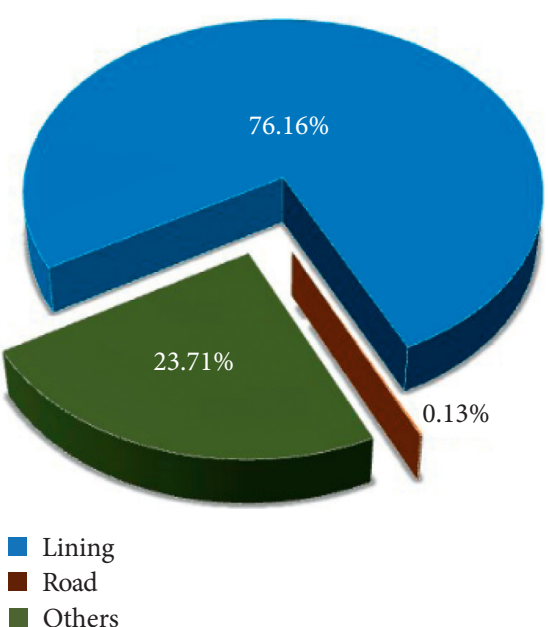

(b)

Figure 2: Percentage distribution of different seismic damage types in the tunnel tube of two highways: (a) Du-Ying Highway; (b) Du-Ying section of National Highway No. 213.

the radius $\left(r_{i}\right)$. In other words, if the damage level of anyone seismic damage type for the $i$ th section is assessed as extremely severe damage, this section should be regarded as extremely severe damage, and the damage level of other seismic damage types for this section is only a supplement to the damage level.

This method can not only take full consideration of the characteristics of tunnel seismic damage but also meet the need of rescue crews for urgently passing the damaged tunnel. Therefore, the determined radius $r_{i}$ is calculated by

$$
r_{i}=\|x\|_{\infty}
$$

where the vector $x=\left(P_{i}, L_{i}, R_{i}, C_{i}\right), \quad i=1,2,3, \ldots, n$, and $n$ is the total number of the divided tunnel sections; $P_{i}, L_{i}, R_{i}$, and $C_{i}$ are the discrete values of four main factors corresponding to the portal and slope damage, the lining damage, the road pavement damage, and the earthquake collapse, respectively; " $\|x\|_{\infty}$ " represents " $\infty$-norm" of the vector $x$ and is calculated by $\|x\|_{\infty}=\max _{1 \leq j \leq m}\left\{\left|x_{j}\right|\right\}$, where $m$ is the total number of elements in the vector $x$.

Step 5: draw the sector domain of each section.

Drawing the sector domain is necessary for comprehensive assessment and classification, as it reflects the contribution of each divided section to the SDL of the whole tunnel; i.e., larger sector domain reflects more severe seismic damage of tunnel. Based on Steps 3 and 4 , the sector domain of each section can be drawn easily in the CCM diagram. The area $S_{i}$ of each sector domain is calculated as

$$
S_{i}=\frac{1}{2} \theta_{i} r_{i}^{2}, \quad i=1,2,3, \ldots, n,
$$

where $r_{i}$ is the damage level of the $i$ th tunnel section; $\theta_{i}$ is the ratio of the length of the $i$ th section to the total length of the tunnel; and $n$ is the total number of sections.

Step 6: assess the SDL of the whole tunnel.

To obtain a more reasonable assessment for the SDL of the whole tunnel, all sector domains of each section in the CCM diagram should be comprehensively analyzed. Herein, another parameter, the sum of effective area $(\Delta S)$, is introduced to reflect the seismic damage of the tunnel as a whole. Clearly, $\Delta S$ is obtained by accumulating all the sector domains of each section as follows:

$$
\Delta S=\sum_{i=1}^{n} S_{i}=\frac{1}{2} \sum_{i=1}^{n}\left(\theta_{i} r_{i}^{2}\right)=\frac{\pi}{l} \sum_{i=1}^{n}\left(l_{i} r_{i}^{2}\right) \text {. }
$$

$\Delta S$ is a geometrical meaning that can be shown in the CCM diagram as a shadow area in Figure 6. In the CCM diagram, each concentric circle represents a seismic damage level, and, if $\Delta S$ is located between two concentric circles, the $\mathrm{SDL}$ of the tunnel is regarded as the lower level represented by the inner circle. Therefore, another parameter, $\alpha$, which is the seismic damage index, is introduced to achieve the rapid assessment of SDL and is expressed as

$$
\alpha=\frac{\Delta S}{S}=\frac{\pi}{l S} \sum_{i=1}^{n}\left(l_{i} r_{i}^{2}\right)=\frac{1}{16 l} \sum_{i=1}^{n}\left(l_{i} r_{i}^{2}\right)
$$

where $S$ is the area of the largest circle with radius 4 in concentric circle diagram $\left(S=\pi \cdot r_{\max }^{2}=16 \pi\right)$. If $\Delta S=S=16 \pi$, the whole tunnel is extremely severely damaged and likely to threaten the safety of the crews and vehicles for emergency rescue. The corresponding relationship between seismic damage index and seismic damage level is shown in Table 2. In addition, the detailed 


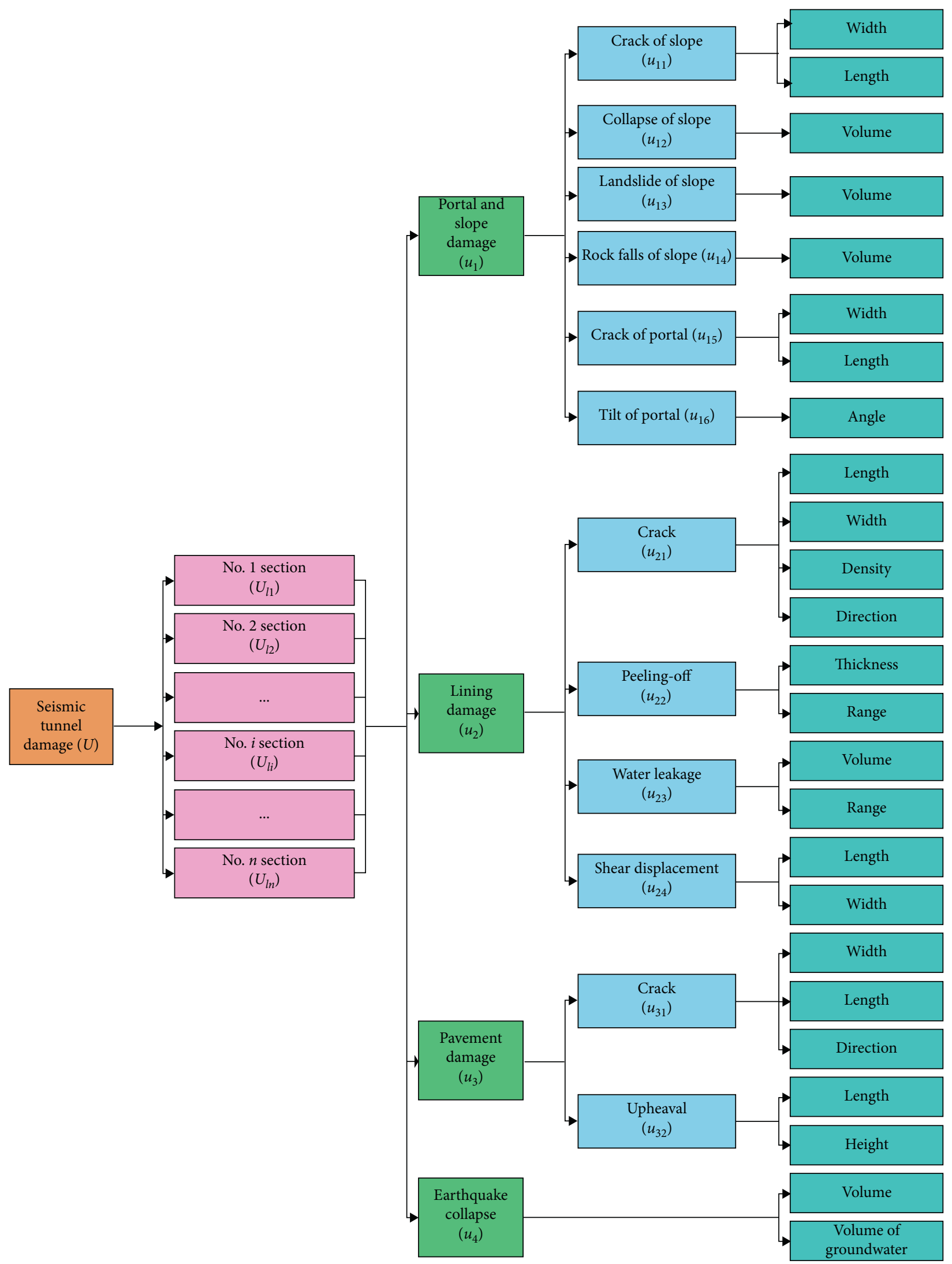

FIGURE 3: Structural diagram of AHP for the rapid assessment of the seismic damage level of tunnels. 


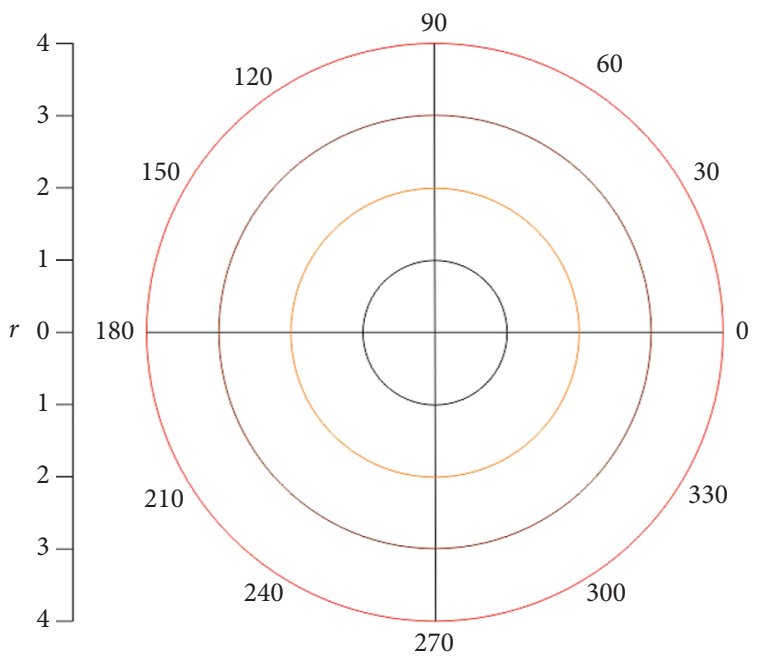

Figure 4: SDL initial diagram based on CCM.

classification criterion of tunnel seismic damage is described in Section 4.5.

In particular, to visually display the classification result, an important parameter called synthetic radius of the SDL $\left(R_{s}\right)$ is introduced and expressed as follows:

$$
R_{S}=\sqrt{\frac{\Delta S}{\pi}}
$$

With the parameter $R_{s}$, not only the assessment and classification result can be visually displayed in the CCM diagram, but also the close degree with higher level in the same level be obtained by comparing $R_{s}$ value. A sample CCM diagram displaying an assessment result of the SDL is shown in Figure 6.

\section{Discretized Assessment Indexes and Classification Criterion}

Selecting appropriate indexes is important for the assessment of the SDL of mountain tunnel, and therefore, some criteria for index selection are quite essential. First of all, the extremely important indexes which directly reflect characteristics of seismic damage and its degree should be selected. Second, the potential factors that can induce severe disaster after an earthquake should also be selected. According to the statistical analysis in the 2nd section on the damage types of mountain tunnels in Wenchuan earthquake, four main seismic damage types, i.e., the portal and slope damage $(P)$, the lining damage $(L)$, the road pavement damage $(R)$, and the earthquake collapse $(C)$, are selected to set up the damage index system. This system covers the main controlling factors affecting the safety of the tunnel structure and emergency rescue after earthquake. Moreover, the independency among indexes is taken into elaborative consideration.

Based on numerical discretization of continuous variables $[7,20]$, the attribute value for the index of each seismic damage type is discretized into several different ranges which, respectively, correspond to the different assessment levels with designated discrete values. The index of each seismic damage type is assessed as five damage levels (i.e., extremely severe, severe, moderate, slight, and undamaged), corresponding to the discrete value of $4,3,2,1$, and 0 . In detail, once an index (such as " $P$ ") for the $i$ th section tunnel is assessed as certain damage level (e.g., "severe"), the corresponding discrete value (e.g., 3 ) is assigned to $P_{i}$ (e.g., $P_{i}=3$ ). In the same way other indexes (e.g., $L_{i}, R_{i}$, and $C_{i}$ ) are also determined, and then $r_{i}$ is calculated using equation (4). The seismic damage level can be identified by the seismic damage description and specific quantitative parameters.

4.1. Portal and Slope Damage $(P)$. The portal and slope damage always occurs at the entry or exit part of tunnel. Due to its location on the ground surface, the tunnel portal structure is subjected to strong earthquake inertial force and thus prone to be damaged. The seismic damage of the portal slope involves collapse, rock fall, landslide, and others and can easily block the tunnel portal and seriously hinder the emergency rescue. On the basis of the present study on the seismic damage of tunnel portal and slope $[14,15]$, the index of seismic damage of tunnel portal and slope $(P)$ is discretized by quantitatively and qualitatively assessing the degree of slope collapse, the volume of rock fall and landslide, and the seismic damage situation of the tunnel portal structure, as shown in Table 3.

4.2. Lining Damage $(L)$. The lining damage mainly includes crack, peeling-off, falling, and collapse. The quantitative characteristics of the damage reflect the seismic damage degree of the lining, and they are described by the density, the width and length of cracks, the scale and range of peeling-off, and collapse. On the basis of the present study on lining damage assessment $[9,14]$, the index of seismic damage of the lining $(L)$ is discretized by quantitatively and qualitatively assessing the length, width and density of crack, the scale and degree of peeling-off, the falling and collapse [24], and the situation of groundwater, as shown in Table 4. 


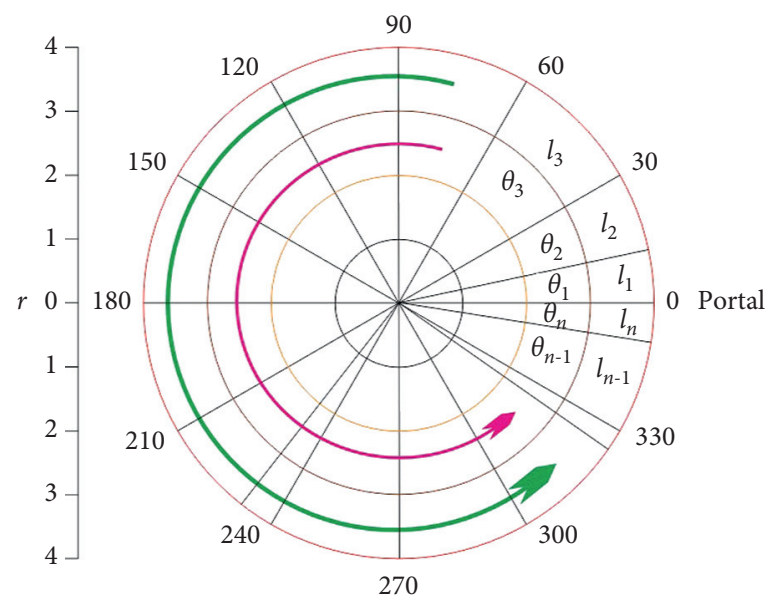

FIGURE 5: The sample diagram of CCM after determining the angle and arc.

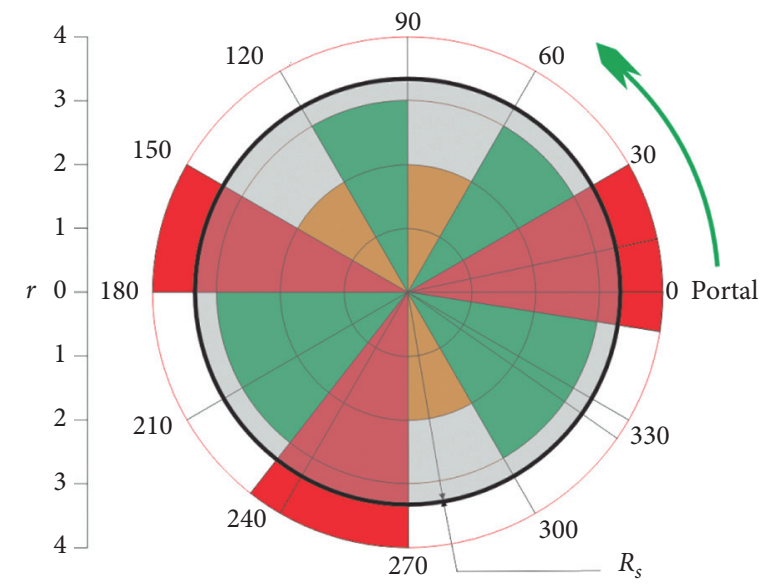

FIgURE 6: A sample CCM diagram with synthetic radius displaying an assessment result.

4.3. Road Pavement Damage (R). The road pavement damage, including crack and upheaval, can seriously hinder the emergency rescue and disaster relief after earthquakes. Reflecting the severity of the pavement damage, the quantitative characteristics of the damage includes the width, the length and extension direction of cracks, the upheaval height, and others. According to the field investigation data and the present study on seismic damage assessment of pavement $[2,6]$, the index of seismic damage of road pavement $(R)$ is discretized by quantitatively and qualitatively assessing the width, length and direction of crack, the height of upheaval $[14,15,24]$, and the situation of ponding water, as shown in Table 5.Note: $l=$ length of crack, $w=$ width of crack or dislocation, and $h=$ height of upheaval or dislocation.

4.4. Earthquake Collapse (C). The tunnel collapse triggered by earthquake is the most severe damage type among all tunnel seismic damages and can hinder and even completely block the rescue vehicles and crews. It takes high cost and long time to repair the collapse of tunnel and surrounding rock. Based on the present study on tunnel earthquake collapse [25-29], the index of tunnel earthquake collapse (C) is discretized by quantitatively and qualitatively assessing the volume, the type and characteristics of collapse, the groundwater situation, and the degree of weathering or fracture of rocks, as shown in Table 6.

4.5. Classification Criterion of Tunnel Seismic Damage. Although some criteria were introduced in different literature studies, up until now, to the knowledge of authors, there lacks a unified standard for the classification of tunnel seismic damage. Dowding and Rozan [30] classified three damage levels, i.e., no damage, minor damage, and damage. Huang et al. [28] and Wang et al. [2] improved the study of Dowding and Rozan's classification by further dividing the minor damage into slight damage and moderate damage. Since the 2008 Wenchuan earthquake, some new classification studies were proposed because extremely severe damages in mountain tunnels, including earthquake collapse and dislocation, have been reported [3,9]. As a result, a new five-level damage classification system (i.e., extremely severe, severe, moderate, slight, and undamaged) was proposed $[2,9,14]$. Based on the abovementioned studies on the 
TABLE 2: Relationship between seismic damage index and seismic damage level of tunnel.

\begin{tabular}{lccccc}
\hline Level & Extremely severe & Severe & Moderate & Slight & Undamaged \\
\hline Index & $\alpha=1$ & $9 / 16<\alpha<1$ & $4 / 16<\alpha<9 / 16$ & $1 / 16<\alpha<4 / 16$ & $0 \leq \alpha<1 / 16$ \\
\hline
\end{tabular}

${ }^{*}$ Standard value of $0,1 / 16,4 / 16,9 / 16$, and 1 is the area ratio of the concentric circles with different radius $(0,1,2,3$, and 4$)$ to the largest concentric circle with radius 4 .

TABLe 3: Discretized assessment index and description of portal and slope damage.

\begin{tabular}{|c|c|c|}
\hline Damage level & Seismic damage description & $\begin{array}{c}\text { Discrete } \\
\text { value }\end{array}$ \\
\hline $\begin{array}{l}\text { Extremely } \\
\text { severe }\end{array}$ & $\begin{array}{l}\text { Extensive failure of slope; extremely severe mountain collapse, landslide and rock fall; completely buried } \\
\text { tunnel portal; extremely severe damage of portal structure (extensive cracks, extremely severe tilt, and } \\
\text { subsidence); completely impassable traffic }\end{array}$ & 4 \\
\hline Severe & $\begin{array}{l}\text { Local failure of slope; large-scale mountain collapse, landslide and rock fall; most part of tunnel portal is } \\
\text { buried; severe damage of portal structure (local cracks, severe tilt, and subsidence); impassable traffic }\end{array}$ & 3 \\
\hline Moderate & $\begin{array}{l}\text { Notable cracks of slope; medium-scale rock fall; massive gravel or large stone piles up in front of portal; } \\
\text { moderate damage of portal structure (local cracks, moderate tilt, and subsidence); passable traffic after } \\
\text { small-scale remediation }\end{array}$ & 2 \\
\hline Slight & $\begin{array}{l}\text { No crack on slope surface; small-scale rock fall; sparse gravels or small stones piles up in front of tunnel } \\
\text { portal; slight damage of portal structure (slight cracks and tilt); passable traffic }\end{array}$ & 1 \\
\hline Undamaged & Undamaged tunnel portal and slope; smooth traffic; no abnormal phenomenon & 0 \\
\hline
\end{tabular}

TABle 4: Discretized assessment index and description of lining damage.

\begin{tabular}{|c|c|c|}
\hline Damage level & Seismic damage description & $\begin{array}{l}\text { Discrete } \\
\text { value }\end{array}$ \\
\hline $\begin{array}{l}\text { Extremely } \\
\text { severe }\end{array}$ & $\begin{array}{c}\text { Intensive crack or dislocation }(l>10 \mathrm{~m}, w>10 \mathrm{~mm}) \text {; developing deformation; cracked vault lining is likely } \\
\text { to fall; crushed vault lining range } S>3 \mathrm{~m}^{2} \text {; extremely severe falling of secondary lining, even massive } \\
\text { collapse to threaten traffic safety; inrushing groundwater }\end{array}$ & 4 \\
\hline Severe & $\begin{array}{c}\text { Crack or dislocation }(5 \mathrm{~m}<l<10 \mathrm{~m}, 5 \mathrm{~mm}<w<10 \mathrm{wmm}) \text {, cracked vault lining is likely to fall; crushed } \\
\text { vault lining range } 1 \mathrm{~m}^{2}<S<3 \mathrm{~m}^{2} \text {; continuously inflowing groundwater }\end{array}$ & 3 \\
\hline Moderate & $\begin{array}{l}\text { Crack or dislocation }(l<5 \mathrm{~m}, 1 \mathrm{~mm}<w<5 \mathrm{~mm}) \text {; small-scale lining peeling-off; crushed vault lining range } \\
\qquad S<1 \mathrm{~m}^{2} ; \text { dripping groundwater }\end{array}$ & 2 \\
\hline Slight & $\begin{array}{c}\text { Crack or dislocation }(w<1 \mathrm{~mm}) \text { but not further development; no crushed vault; slight seepage of } \\
\text { groundwater }\end{array}$ & 1 \\
\hline Undamaged & No cracks or crush; no groundwater seepage; no abnormal phenomenon & 0 \\
\hline
\end{tabular}

Note: $L=$ length of crack, $w=$ width of crack, and $S=$ area of crushed range.

assessment and classification of tunnel seismic damage and referred to the Chinese railway and highway industry standards for tunnel performance degradation [12, 24, 31], the SDL of mountain tunnel is discretized in this study as shown in Table 7.

\section{Application of CCM}

The Wenchuan earthquake caused severe damages to tens of mountain tunnels. Due to the lack of rapid and accurate assessment of tunnel seismic damage, the emergency rescue and damage repair after the earthquake were seriously hindered. In order to demonstrate the applicability and accuracy of the rapid assessment method of CCM proposed in this study, we chose the Longxi tunnel as an example to assess and classify the seismic damage. Longxi tunnel is located near the epicenter of Wenchuan earthquake as shown in Figure 7, being in the south of Chaping Mountain between Yingxiu Town and Longxi Town and to the left bank of the Minjiang River in Sichuan Province of China. The tunnel axis direction is northwest (NW), and mountain ridge direction is northeast (NE), namely, there exists a large intersection angle between the two axes. The distance between the tunnel exit and the Wenchuan earthquake epicenter (i.e., Yingxiu Town) is only $4 \mathrm{~km}$.

Because of its typical geographical location and representative seismic damage type of Longxi tunnel during the Wenchuan earthquake, some scholars have investigated the seismic damage characteristics of Longxi tunnel and the associated mechanisms [3, 9, 32-37]; however, systematic assessment and classification study on seismic damage of Longxi tunnel was rarely conducted. Although Longxi tunnel is a double-line tunnel, the field investigation on the right line tunnel could not be carried out as the right line encountered severe earthquake collapse during Wenchuan earthquake. Therefore, only the left line of the tunnel is used here to conduct the SDL assessment, and the length to be assessed is $3492 \mathrm{~m}$.

Based on the field investigation data for the left line of Longxi tunnel after earthquake, the relevant parameters of 
Table 5: Discretized assessment index and description of pavement damage.

\begin{tabular}{|c|c|c|}
\hline Damage level & Seismic damage description & $\begin{array}{c}\text { Discrete } \\
\text { value }\end{array}$ \\
\hline $\begin{array}{l}\text { Extremely } \\
\text { severe }\end{array}$ & $\begin{array}{c}\text { Extensive and intensive cracks }(l>20 \mathrm{~m}, w>5 \mathrm{~cm}) \text {; pavement upheaval }(h>50 \mathrm{~cm}) \text {; local dislocation } \\
(w>5 \mathrm{~cm}, h>10 \mathrm{~cm}) \text {; extremely severe damage to pavement; pavement covered by deep and extensive } \\
\text { ponding water; impassable traffic }\end{array}$ & 4 \\
\hline Severe & $\begin{array}{c}\text { Intensive cracks }(10 \mathrm{~m}<l<20 \mathrm{~m}, 1 \mathrm{~cm}<w>5 \mathrm{~cm}) \text {; pavement upheaval }(10 \mathrm{~cm}<h<50 \mathrm{~cm}) \text {; local } \\
\text { dislocation }(1 \mathrm{~cm}<w>5 \mathrm{~cm}, 5 \mathrm{~cm}<h<10 \mathrm{~cm}) \text {; severe damage to pavement; extensive ponding water; } \\
\text { cautiously passable traffic with high risk }\end{array}$ & 3 \\
\hline Moderate & $\begin{array}{c}\text { Local cracks }(5 \mathrm{~m}<l<10 \mathrm{~m}, 0.5 \mathrm{~cm}<w>1 \mathrm{~cm}) \text {; pavement upheaval }(h<10 \mathrm{~cm}) \text {; local dislocation } \\
(w>1 \mathrm{~cm}, 1 \mathrm{~cm}<h<5 \mathrm{~cm}) ; \text { small-scale damage to pavement; local pavement covered by ponding water; } \\
\text { cautiously passable traffic by safety measures }\end{array}$ & 2 \\
\hline Slight & $\begin{array}{c}\text { Local cracks }(l<5 \mathrm{~m}, w<0.5 \mathrm{~cm}) \text {; no pavement upheaval; few dislocation }(w<0.5 \mathrm{~cm}, h<1 \mathrm{~cm}) \text {; little } \\
\text { damage to pavement; local pavement covered by less ponding water; passable traffic but maintenance still } \\
\text { needed }\end{array}$ & 1 \\
\hline Undamaged & No crack or upheaval; passable traffic; no abnormal phenomenon & 0 \\
\hline
\end{tabular}

TABLE 6: Discretized assessment index and description of tunnel collapse.

\begin{tabular}{lcc}
\hline Damage level & Seismic damage description & $\begin{array}{c}\text { Discrete } \\
\text { value }\end{array}$ \\
\hline $\begin{array}{l}\text { Extremely } \\
\text { severe }\end{array}$ & $\begin{array}{r}\text { Collapse }\left(v>5000 \mathrm{~m}^{3}\right) \text {; extensive and massive groundwater inrush; strong weathering or severe fractures } \\
\text { of rock, extremely unstable collapse cavity; necessary measures should be taken immediately }\end{array}$ & $\begin{array}{r}\text { Collapse }\left(1000 \mathrm{~m}^{3}<v<5000 \mathrm{~m}^{3}\right) ; \text { local groundwater inflow; strong weathering or severe fractures of rock, } \\
\text { unstable collapse cavity; necessary measures should be taken }\end{array}$ \\
\hline $\begin{array}{r}\text { Severe } \\
\text { Moderate }\end{array}$ & $\begin{array}{r}\text { Collapse }\left(300 \mathrm{~m}^{3}<v<1000 \mathrm{~m}^{3}\right) ; \text { local groundwater dripping; moderate weathering or a number of } \\
\text { fractures of rock; poor stability of collapse cavity; measures should be taken as early as possible }\end{array}$ & 2 \\
\hline Slight & $\begin{array}{r}\text { Collapse }\left(v<100 \mathrm{~m}^{3}\right) ; \text { local groundwater leakage or seepage; good stability of collapse cavity; slight } \\
\text { weathering or few fractures of rock; measures should be taken in time }\end{array}$ & 1 \\
\hline Undamaged & No collapse or groundwater; no abnormal phenomenon & 0 \\
\hline
\end{tabular}

Note: $v=$ volume of tunnel collapse.

different tunnel sections are calculated using the proposed CCM rapid assessment (Table 8).

Based on the seismic damage description and discretized assessment parameters of SDL as shown in Table 8, the rapid assessment of SDL for the left line of Longxi tunnel is carried out according to the following procedure:

Step 1: draw the initial CCM diagram.

Step 2: divide the Longxi tunnel into 62 different sections (Table 8 ) according to the type and degree of seismic damage, namely,

$$
l=l_{1}+l_{2}+l_{3}+\cdots+l_{i}+\cdots+l_{62} .
$$

Step 3: assign proportional angle and arc for each section according to its length (Figure 8).

Step 4: calculate the SDL $\left(r_{i}\right)$ of each section using equation (3) according to the comprehensive assessment system and indexes $(P, L, R$, and $C)$ proposed in this paper, and the $r_{i}$ values are shown in Table 8 .

Step 5: draw each sector domain in the CCM diagram to represent the seismic damage situation of each tunnel section.
Step 6: calculate the seismic damage index $(\alpha)$ and synthetic radius $\left(R_{s}\right)$ by equations (6) and (7), respectively, which are equal to 0.584 and 3.06 . It is clear that the value of $\alpha$ is located between $9 / 16$ and 1 according to Table 2, which shows that the seismic damage of the left line of Longxi tunnel is severe. Namely, severe performance degradation of tunnel structure occurred and traffic safety was threatened, and remedial measures should be taken as soon as possible. The synthetic radius for the classification of seismic damage is labelled in the CCM diagram, and the result is visualized in Figure 9.

According to the field investigation data, the left line of Longxi tunnel suffered from severe seismic damage during Wenchuan earthquake, including slope collapse, rock falls, crack and collapse of lining, crack and upheaval of invert, large-scale surrounding rock collapse, and others (Figure 10). The seismic damage significantly lowered the tunnel structural safety and traffic safety and hindered rescue and remedial work after the earthquake. Shown in this case study, the assessment results from the CCM are consistent with those of the field investigation, which verifies the 
TABLe 7: Discretized SDL and description of mountain tunnel.

\begin{tabular}{|c|c|c|}
\hline SDL & Seismic damage description & $\begin{array}{c}\text { Discrete } \\
\text { value }\end{array}$ \\
\hline $\begin{array}{l}\text { Extremely } \\
\text { severe }\end{array}$ & $\begin{array}{c}\text { Extremely severe degradation and damage of tunnel structure; completely impassable traffic; necessary } \\
\text { measures should be taken immediately, otherwise further aggravating SDL }\end{array}$ & 4 \\
\hline Severe & $\begin{array}{l}\text { Severe degradation and damage of tunnel structure; traffic safety threatened severely; measures should be } \\
\text { taken as early as possible, otherwise further aggravating SDL }\end{array}$ & 3 \\
\hline Moderate & $\begin{array}{l}\text { Moderate degradation and damage of tunnel structure; traffic safety threatened moderately; measures } \\
\text { should be taken in time, otherwise further aggravating SDL }\end{array}$ & 2 \\
\hline Slight & $\begin{array}{l}\text { Slight degradation and damage of tunnel structure; traffic safety guaranteed slightly, normal usage } \\
\text { unaffected; targeted and key monitoring necessary }\end{array}$ & 1 \\
\hline Undamaged & Undamaged tunnel; no abnormal phenomenon & 0 \\
\hline
\end{tabular}

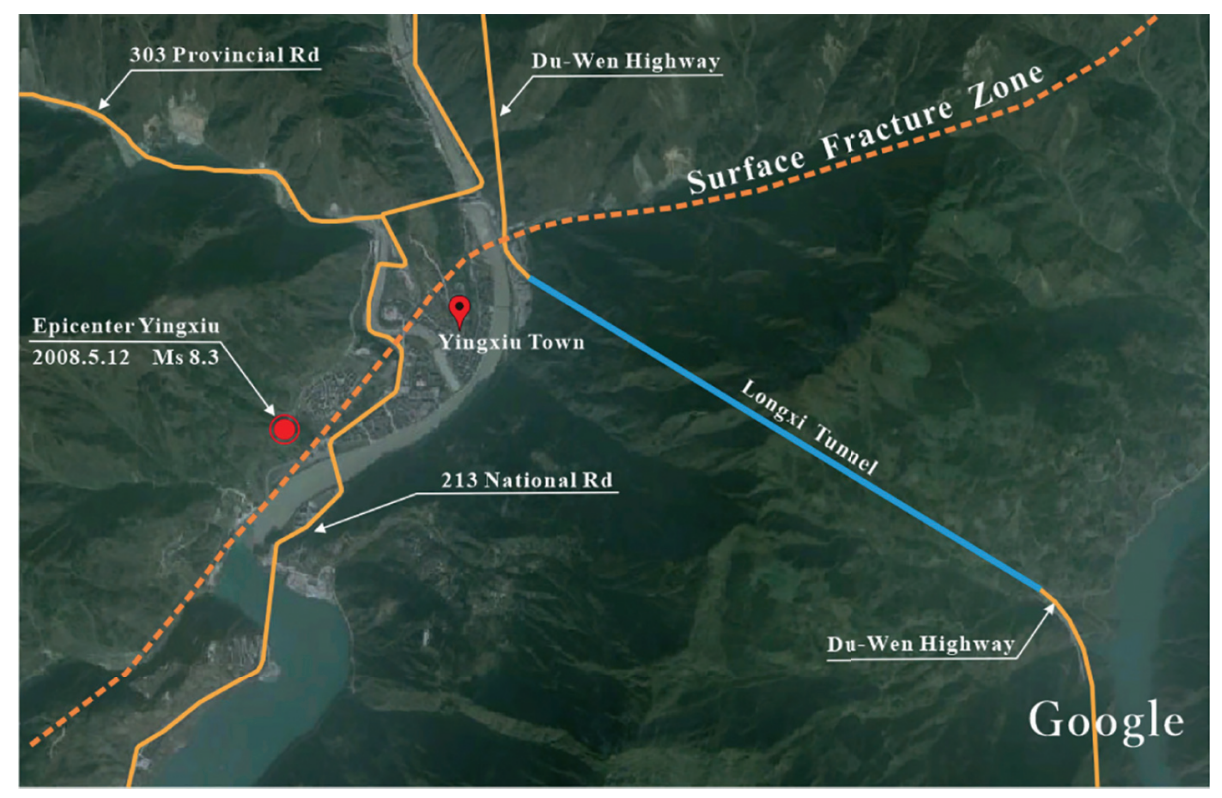

Figure 7: The geographical location of Longxi tunnel and the epicenter of Wenchuan earthquake (from Google Map).

Table 8: The seismic damage description and assessment parameters of SDL for the left line of Longxi tunnel.

\begin{tabular}{|c|c|c|c|c|c|c|c|c|}
\hline Section & Stake & $\begin{array}{c}\mathrm{l}_{\mathrm{i}} \\
(\mathrm{m})\end{array}$ & Seismic damage description & & $L_{i}$ & $R_{i}$ & $\begin{array}{l}\text { lue } \\
C_{i}\end{array}$ & \\
\hline 1 & $\mathrm{LK} 21+420 \sim 470$ & 50 & $\begin{array}{l}\text { Intensive crack of pavement at entry portal; intensive and dense cracks }(1 \mathrm{~mm}<w \\
<10 \mathrm{~mm}) \text { on secondary lining in different directions; large-scale secondary lining } \\
\text { peeling-off, falling and collapse; local leakage of groundwater; construction joints } \\
\text { dislocation }(h=10 \mathrm{~cm}) .\end{array}$ & 4 & 4 & 3 & 0 & 4 \\
\hline 2 & $\mathrm{LK} 21+470 \sim 575$ & 105 & $\begin{array}{l}\text { Intense upheaval of pavement is as high as about } 1.2 \text { meter; intensive and dense } \\
\text { cracks }(1 \mathrm{~mm}<w<10 \mathrm{~mm}) \text { on secondary lining in different directions; large-scale } \\
\text { secondary lining peeling-off, falling and collapse; local leakage of groundwater; } \\
\text { construction joints dislocation }(h=10 \mathrm{~cm}) \text { (Figures } 10(\mathrm{a}) \text {, and } 10(\mathrm{~b})) \text {. }\end{array}$ & 4 & 4 & 4 & 0 & 4 \\
\hline 3 & $\mathrm{LK} 21+575 \sim 620$ & 45 & $\begin{array}{l}\text { Large-scale earthquake collapse of surrounding rock; secondary lining collapse; } \\
\text { invert upheaval }(h=10 \mathrm{~cm}) .\end{array}$ & 0 & 4 & 2 & 4 & 4 \\
\hline 4 & $\mathrm{LK} 21+620 \sim 670$ & 50 & $\begin{array}{l}\text { Extensive collapse of secondary lining; primary support grid exposed, deformed } \\
\text { and distorted. }\end{array}$ & 0 & 4 & 0 & 4 & 4 \\
\hline 5 & LK21 + $670 \sim 695$ & 25 & $\begin{array}{l}\text { Large-scale earthquake collapse; secondary lining collapse; invert upheaval } \\
\qquad(h=120 \mathrm{~cm})(\text { Figure } 10(\mathrm{c})) .\end{array}$ & 0 & 4 & 4 & 4 & \\
\hline 6 & & 60 & Cracks $(w=3 \mathrm{~cm})$ and peeling-off of secondary lining; invert upheaval $(h=80 \mathrm{~cm})$. & 0 & 3 & 4 & 0 & \\
\hline 7 & $\mathrm{LK} 21+755 \sim 780$ & 25 & Invert upheaval $(h=80 \mathrm{~cm})$ & 0 & 0 & 4 & 0 & \\
\hline 8 & $\mathrm{LK} 21+780 \sim 880$ & 100 & $\begin{array}{c}\text { Dense cracks; several peeling-off and collapse occurred at vault of secondary lining; } \\
\text { invert upheaval }(h=80 \mathrm{~cm}) .\end{array}$ & 0 & 4 & 4 & 0 & \\
\hline 9 & $\mathrm{LK} 21+880 \sim 890$ & 10 & Invert upheaval $(h=80 \mathrm{~cm})$ & 0 & 0 & 4 & 0 & \\
\hline
\end{tabular}


TABle 8: Continued.

\begin{tabular}{|c|c|c|c|c|c|c|c|c|}
\hline Section & Stake & $\begin{array}{l}l_{\mathrm{i}} \\
(\mathrm{m})\end{array}$ & Seismic damage description & & $\begin{array}{l}\text { Idex } \\
L_{i}\end{array}$ & val & ue & \\
\hline 10 & $\begin{array}{l}\mathrm{LK} 21+890 \sim \\
\mathrm{LK} 22+285\end{array}$ & 395 & Secondary lining collapse; intense invert upheaval $(h=80 \mathrm{~cm})$ to triangle in shape. & 0 & 4 & 4 & 0 & 4 \\
\hline 11 & $\mathrm{LK} 22+285 \sim 320$ & 35 & $\begin{array}{c}\text { Invert dislocation }(h=15 \mathrm{~cm}) ; \begin{array}{l}\text { longitudinal crack of pavement above central } \\
\text { drainage ditch. }\end{array}\end{array}$ & 0 & 0 & 4 & 0 & 4 \\
\hline 12 & $\mathrm{LK} 22+320 \sim 335$ & 15 & $\begin{array}{l}\text { Collapse and transverse cracks }(w=1 \mathrm{~cm}) \text { of secondary lining; invert dislocation } \\
\qquad(h=15 \mathrm{~cm})\end{array}$ & 0 & 4 & 4 & 0 & 4 \\
\hline 13 & $\mathrm{LK} 22+335 \sim 385$ & 50 & Undamaged; no abnormal phenomenon. & 0 & 0 & 0 & 0 & 0 \\
\hline 14 & $\mathrm{LK} 22+385 \sim 470$ & 85 & $\begin{array}{c}\text { Local collapse of secondary lining; longitudinal crack }(l>70 \mathrm{~m}, w=2 \mathrm{~cm}) \text { of } \\
\text { pavement above central drainage ditch. }\end{array}$ & 0 & 3 & 3 & 0 & 3 \\
\hline 15 & $\mathrm{LK} 22+470 \sim 590$ & 120 & Undamaged; no abnormal phenomenon. & 0 & 0 & 0 & 0 & 0 \\
\hline 16 & $\mathrm{LK} 22+590 \sim 680$ & 90 & $\begin{array}{l}\text { Intense invert upheaval }(h=30 \mathrm{~cm}) \text { to almost triangle in shape; longitudinal crack } \\
\qquad(w=1 \mathrm{~cm}) \text { of pavement above central drainage ditch. }\end{array}$ & 0 & 0 & 3 & 0 & 3 \\
\hline 17 & $\mathrm{LK} 22+680 \sim 754$ & 74 & $\begin{array}{l}\text { Longitudinal cracks }(l>40 \mathrm{~m}, 1 \mathrm{~cm}<w<3 \mathrm{~cm}) \text { on secondary lining; extensive } \\
\text { falling of secondary lining; intense invert upheaval }(h=30 \mathrm{~cm}) \text { to almost triangle in } \\
\text { shape; longitudinal crack }(w=1 \mathrm{~cm}) \text { of pavement above central drainage ditch. }\end{array}$ & 0 & 4 & 3 & 0 & 4 \\
\hline 18 & LK22 + $754 \sim 845$ & 91 & $\begin{array}{l}\text { Invert upheaval }(h=30 \mathrm{~cm}) \text {, intense deformation to almost triangle in shape; } \\
\text { longitudinal crack }(w=1 \mathrm{~cm}) \text { of pavement above central drainage ditch. }\end{array}$ & 0 & 0 & 3 & 0 & 3 \\
\hline 19 & $\mathrm{LK} 22+845 \sim 877$ & 32 & $\begin{array}{l}\text { Invert upheaval }(h=30 \mathrm{~cm}) \text {, intense deformation to almost triangle in shape; } \\
\text { longitudinal crack }(w=1 \mathrm{~cm}) \text { of pavement above central drainage ditch. }\end{array}$ & 0 & 0 & 3 & 0 & 3 \\
\hline 20 & $\mathrm{LK} 22+877 \sim 902$ & 25 & $\begin{array}{l}\text { Primary support collapse; steel arch exposed, severe deformation and distortion; } \\
\text { invert upheaval }(h=30 \mathrm{~cm}) \text {, intense deformation to almost triangle in shape; } \\
\text { longitudinal crack }(w=1 \mathrm{~cm}) \text { of pavement above central drainage ditch. }\end{array}$ & 0 & 4 & 3 & 0 & 4 \\
\hline 21 & $\mathrm{LK} 22+902 \sim 915$ & 13 & Undamaged; no abnormal phenomenon. & 0 & 0 & 0 & 0 & 0 \\
\hline 22 & $\begin{array}{l}\mathrm{LK} 22+915 \sim \\
\mathrm{LK} 23+010\end{array}$ & 95 & $\begin{array}{c}\text { Large-scale collapse of primary support; steel arch exposed, severe deformation } \\
\text { and distortion. }\end{array}$ & 0 & 4 & 0 & 0 & 4 \\
\hline 23 & $\mathrm{LK} 23+176 \sim 330$ & 154 & $\begin{array}{c}\text { Severe damage of primary support; severe deformation and distortion of steel arch; } \\
\text { large-scale falling of spray concrete. }\end{array}$ & 0 & 4 & 0 & 0 & 4 \\
\hline 24 & $\mathrm{LK} 23+330 \sim 340$ & 10 & Undamaged; no abnormal phenomenon. & 0 & 0 & 0 & 0 & 0 \\
\hline 25 & $\mathrm{LK} 23+340 \sim 570$ & 230 & $\begin{array}{l}\text { Extensive and dense ring cracks }(1 \mathrm{~mm}<w<3 \mathrm{~mm}) \text {; longitudinal cracks on } \\
\text { pavement }(w=8 \mathrm{~mm}) \text {; several cracks of construction joints. }\end{array}$ & 0 & 3 & 1 & 0 & 3 \\
\hline 26 & $\mathrm{LK} 23+570 \sim 625$ & 55 & Undamaged; no abnormal phenomenon. & 0 & 0 & 0 & 0 & 0 \\
\hline 27 & LK23 + 625 675 & 50 & $\begin{array}{c}\text { Extensive cracks, water leakage and collapse of primary support; severe } \\
\text { deformation and distortion of steel arch. }\end{array}$ & 0 & 3 & 0 & 0 & 3 \\
\hline 28 & $\mathrm{LK} 23+675 \sim 680$ & 5 & Secondary lining peeling-off occurred at construction joints. & 0 & 3 & 0 & 0 & 3 \\
\hline 29 & $30 \sim 695$ & 15 & Undamaged; no abnormal phenomenon. & 0 & 0 & 0 & 0 & 0 \\
\hline 30 & $5 \sim 701$ & 6 & on secondary lining. & 0 & 0 & 1 & 0 & 1 \\
\hline 31 & $\mathrm{~K} 23+701 \sim 865$ & 164 & Undamaged; no abnormal phenomenon. & 0 & 0 & 0 & 0 & 0 \\
\hline 32 & $\mathrm{LK} 23+865 \sim 895$ & 30 & Cracks $(w=4 \mathrm{~mm})$ of secondary lining; invert upheaval $(h=15 \mathrm{~cm})$. & 0 & 2 & 3 & 0 & 3 \\
\hline 33 & $\begin{array}{l}\mathrm{LK} 23+895 \sim \\
\mathrm{LK} 24+245\end{array}$ & 350 & Undamaged; no abnormal phenomenon. & 0 & 0 & 0 & 0 & 0 \\
\hline 34 & $\mathrm{LK} 24+245 \sim 275$ & 30 & Large-scale falling & 0 & 4 & 0 & 0 & 4 \\
\hline 35 & $\mathrm{LK} 24+275 \sim 310$ & 35 & Undamaged; no abnormal phenomenon. & 0 & 0 & 0 & 0 & 0 \\
\hline 36 & $\mathrm{LK} 24+310 \sim 350$ & 40 & $\begin{array}{c}\text { Longitudinal cracks }(l>10 \mathrm{~m}, w=4 \mathrm{~mm}) \text { on secondary lining vault; long invert } \\
\text { upheaval }(l>12 \mathrm{~m}) .\end{array}$ & 0 & 2 & 3 & 0 & 3 \\
\hline 37 & $\mathrm{LK} 24+350 \sim 365$ & 15 & normal phenomenon. & 0 & 0 & 0 & 0 & 0 \\
\hline 38 & $\mathrm{LK} 24+365 \sim 370$ & 5 & Transverse cracks $(w=4 \mathrm{~mm})$ on pavement. & 0 & 0 & 1 & 0 & 1 \\
\hline 39 & $\mathrm{LK} 24+370 \sim 390$ & 20 & Undamaged; no abnormal phenomenon. & 0 & 0 & 0 & 0 & 0 \\
\hline 40 & $\mathrm{LK} 24+390 \sim 395$ & 5 & Cracks $(w=2 \mathrm{~mm})$ on secondary lining; transverse cracks $(w=2 \mathrm{~cm})$ on pavement. & 0 & 2 & 3 & 0 & 3 \\
\hline 41 & $\mathrm{LK} 24+395 \sim 405$ & 10 & Undamaged; no abnormal phenomenon. & 0 & 0 & 0 & 0 & 0 \\
\hline 42 & $\mathrm{LK} 24+405 \sim 410$ & 5 & Transverse cracks $(w=5 \mathrm{~cm})$ of invert. & 0 & 0 & 4 & 0 & 4 \\
\hline 43 & $\mathrm{LK} 24+410 \sim 450$ & 40 & Undamaged; no abnormal phenomenon. & 0 & 0 & 0 & 0 & 0 \\
\hline 44 & $\mathrm{LK} 24+450 \sim 550$ & 100 & Large-scale falling and collaps & 0 & 4 & 1 & 0 & 4 \\
\hline 45 & $\mathrm{LK} 24+550 \sim 565$ & 15 & $v<4 \mathrm{~mm}$ ) on secondary lining. & 0 & 3 & 0 & 0 & 3 \\
\hline 46 & $\mathrm{LK} 24+565 \sim 690$ & 125 & Slight cracks on secondary lining. & 0 & 2 & 0 & 0 & 2 \\
\hline 47 & $\mathrm{LK} 24+690 \sim 715$ & 25 & Large-scale falling and collapse at secondary lining vault. & 0 & 4 & 0 & 0 & 4 \\
\hline 48 & $\mathrm{LK} 24+715 \sim 730$ & 15 & Undamaged; no abnormal phenomenon. & 0 & 0 & 0 & 0 & 0 \\
\hline 49 & $\mathrm{LK} 24+730 \sim 735$ & 5 & Slight cracks on secondary lining. & 0 & 2 & 0 & 0 & 2 \\
\hline 50 & LK24 + $735 \sim 755$ & 20 & Undamaged; no abnormal phenomenon. & 0 & 0 & 0 & 0 & 0 \\
\hline
\end{tabular}


TABLE 8: Continued.

\begin{tabular}{|c|c|c|c|c|c|c|c|c|}
\hline Section & Stake & $\begin{array}{c}\mathrm{l}_{\mathrm{i}} \\
(\mathrm{m})\end{array}$ & Seismic damage description & & $L_{i}$ & $R_{i}$ & $C_{i}$ & \\
\hline 51 & $\mathrm{LK} 24+755 \sim 760$ & 5 & Cracks $(w=6 \mathrm{~mm})$ on secondary lining. & 0 & 3 & 0 & 0 & 3 \\
\hline 52 & $\mathrm{LK} 24+760 \sim 790$ & 30 & Undamaged; no abnormal phenomenon. & 0 & 0 & 0 & 0 & 0 \\
\hline 53 & $\mathrm{LK} 24+790 \sim 806$ & 16 & $\begin{array}{c}\text { Cracks }(4 \mathrm{~mm}<w<10 \mathrm{~mm}) \text { on secondary lining; transverse cracks }(w=3 \mathrm{~cm}) \text { of } \\
\text { invert. }\end{array}$ & 0 & 2 & 3 & 0 & 3 \\
\hline 54 & $\mathrm{LK} 24+806 \sim 835$ & 29 & Transverse cracks $(w=3 \mathrm{~cm})$ of invert. & 0 & 0 & 3 & 0 & 3 \\
\hline 55 & $\mathrm{LK} 24+835 \sim 840$ & 5 & Cracks $(w=5 \mathrm{~mm})$ on secondary lining; transverse cracks of invert. & 0 & 3 & 2 & 0 & 3 \\
\hline 56 & $\mathrm{LK} 24+840 \sim 868$ & 28 & Transverse cracks $(w=2 \mathrm{~cm})$ of invert. & 0 & 0 & 3 & 0 & 3 \\
\hline 57 & $\mathrm{LK} 24+868 \sim 870$ & 2 & Cracks $(w=10 \mathrm{~mm})$ on secondary lining. & 0 & 3 & 2 & 0 & 3 \\
\hline 58 & $\mathrm{LK} 24+870 \sim 890$ & 20 & $\begin{array}{c}\text { Large-scale collapse of secondary lining; cracks of the pavement above central } \\
\text { drainage ditch. }\end{array}$ & 0 & 4 & 2 & 0 & 4 \\
\hline 59 & $\mathrm{LK} 24+890 \sim 965$ & 75 & Extensive peeling-off and falling on secondary lining; transverse cracks of invert. & 0 & 3 & 3 & 0 & 3 \\
\hline 60 & $\begin{array}{l}\mathrm{LK} 24+965 \sim \\
\mathrm{LK} 25+010\end{array}$ & 45 & $\begin{array}{c}\text { Cracks }(w=10 \mathrm{~mm}) \text { on secondary lining; cracks of the pavement above central } \\
\text { drainage ditch. }\end{array}$ & 0 & 3 & 2 & 0 & 3 \\
\hline 61 & $\mathrm{LK} 25+010 \sim 048$ & 38 & $\begin{array}{c}\text { Extensive and dense oblique cracks ( } w \text { up to } 30 \mathrm{~mm} \text { ), falls and collapse of lining } \\
\text { vault; cracks and dislocation ( } w \text { up to } 4 \mathrm{~cm} \text { ) of invert. }\end{array}$ & 0 & 4 & 3 & 0 & 4 \\
\hline 62 & LK25 + $048 \sim 078$ & 30 & $\begin{array}{l}\text { Extensive and dense oblique cracks ( } w \text { up to } 30 \mathrm{~mm} \text { ), falls and collapse of lining } \\
\text { vault; cracks and dislocation ( } w \text { up to } 4 \mathrm{~cm} \text { ) of invert; mountain collapse, a large } \\
\text { amount of huge stone piled up in front of portal (Figure 10(d)). }\end{array}$ & 4 & 4 & 3 & 0 & \\
\hline
\end{tabular}

Note: $h=$ height of upheaval or dislocation, $l=$ length of crack or upheaval, and $w=$ width of crack or dislocation.

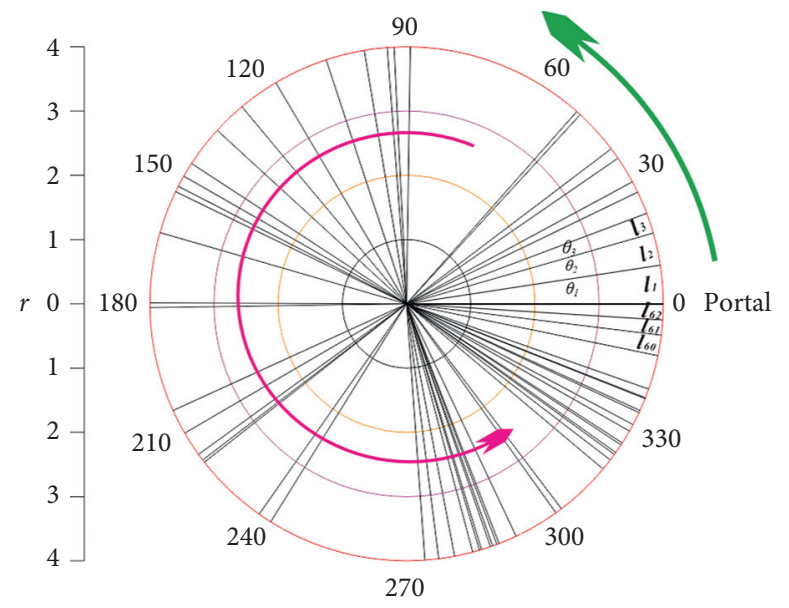

Figure 8: Concentric circle model diagram with proportional angle and arc length.

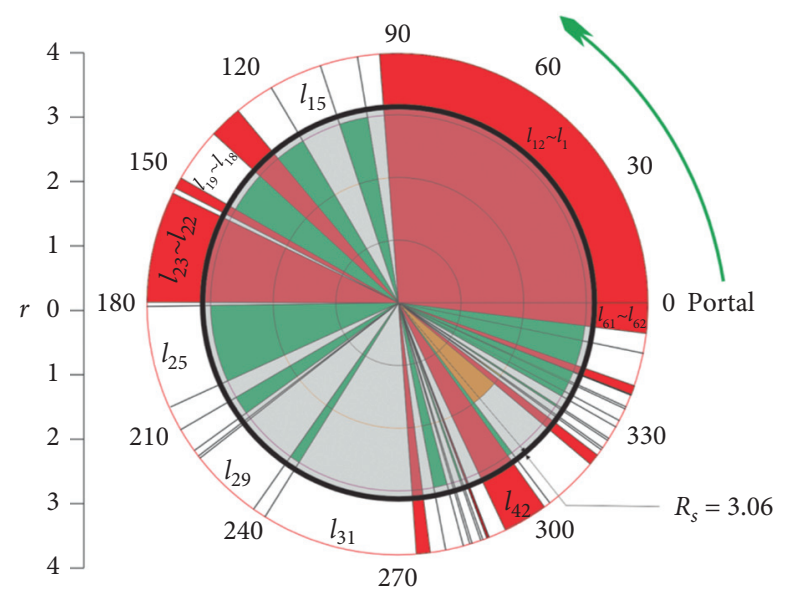

Figure 9: The CCM diagram for the SDL of the left line of Longxi tunnel. 


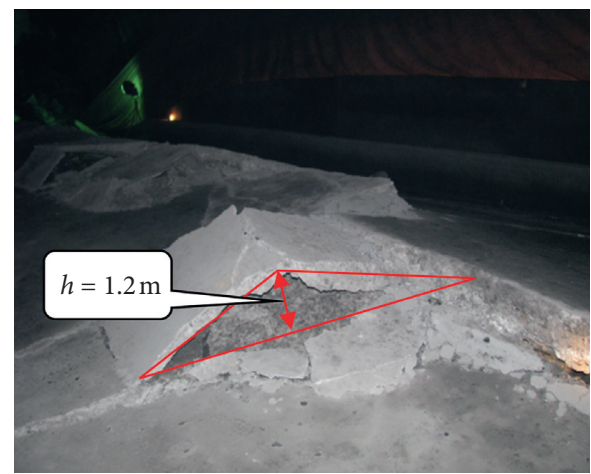

(a)

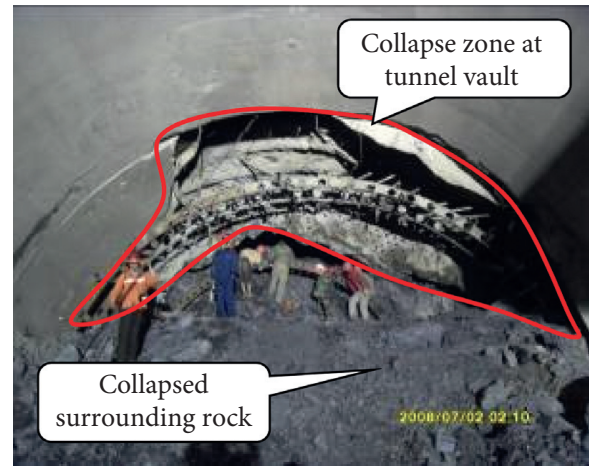

(c)

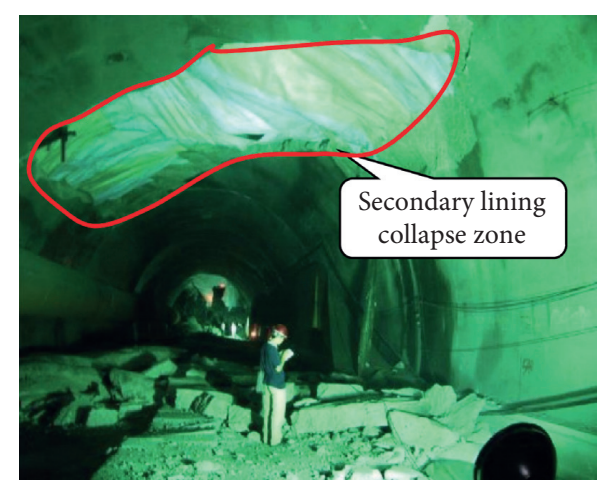

(b)

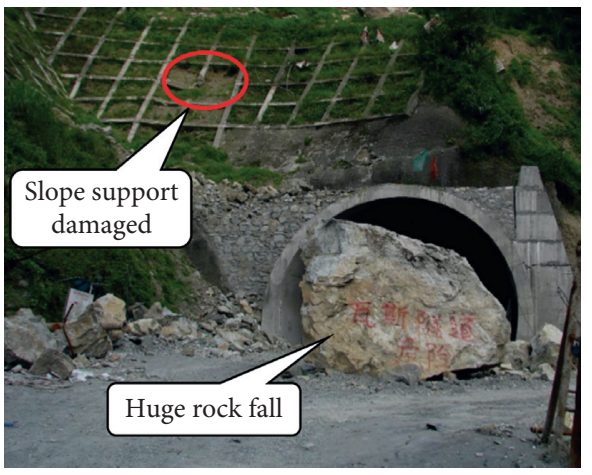

(d)

FIgURE 10: The main seismic damage of the left line of Longxi tunnel: (a) severe upheaval and tensile fractures of the invert arch pavement at LK21 + 521 552, (b) collapse of the arch secondary lining at LK21 + 540 558, (c) collapse of surrounding rock and lining at LK21 + 670 695, and (d) huge rock falls at Longxi tunnel.

accuracy and applicability of the CCM assessment method for the seismic damage level.

\section{Conclusions}

Based on the techniques of analytic hierarchy process (AHP) and numerical discretization, the concentric circle method (CCM) is proposed to rapidly assess the seismic damage level (SDL) of mountain tunnel. The proposed method can rapidly and accurately assess the SDL of mountain tunnel to win over precious time for emergency rescue and provide references for the repair of damaged tunnel.

According to the statistical analysis on the damage characteristics and types of 40 mountain tunnels during Wenchuan earthquake, a set of effective assessment and classification system covering complete multilevel factor sets and specific quantitative parameters is established. Four main damage types, including the slope and portal damage, the lining damage, the road pavement damage, and the earthquake collapse, are defined as the level-1 controlling factor sets. To target the feature of rapidity for the assessment of SDL of mountain tunnel, the discretized assessment index and classification criterion are introduced and fully considered in this study.
Using the proposed concentric circle method (CCM), the SDL of the left line of Longxi tunnel after Wenchuan earthquake is used as an example and is identified to be severe damage. The assessment results from the proposed rapid assessment method are consistent with the field investigation data, verifying the accuracy and applicability of the CCM for rapid assessment of seismic damage of mountain tunnel.

\section{Data Availability}

The data used to support the findings of this study are included within the article.

\section{Conflicts of Interest}

The authors declare that they have no conflicts of interest.

\section{Acknowledgments}

This study was financially supported by the National Key Research and Development Program of China (2016YFB1200401-102D), Western Construction Project of the Ministry of Transport (grant no. 2015318 J29 040), and the Open Foundation of State Key Laboratory of Geohazard 
Prevention and Geoenvironment Protection (Chengdu University of Technology, grant no. SKLGP2011K014).

\section{References}

[1] K. Yashiro, Y. Kojima, and M. Shimizu, "Historical earthquake damage to tunnels in Japan and case studies of railway tunnels in the 2004 Niigataken-Chuetsu earthquake," Quarterly Report of RTRI, vol. 48, no. 3, pp. 136-141, 2007.

[2] W. L. Wang, T. T. Wang, J. J. Su, C. H. Lin, C. R. Seng, and T. H. Huang, "Assessment of damage in mountain tunnels due to the Taiwan Chi-Chi Earthquake," Tunnelling and Underground Space Technology, vol. 16, no. 3, pp. 133-150, 2001.

[3] T. Li, "Damage to mountain tunnels related to the Wenchuan earthquake and some suggestions for aseismic tunnel construction," Bulletin of Engineering Geology and the Environment, vol. 71, no. 2, pp. 297-308, 2012.

[4] S. Senzai, O. Hajime, and M. Takashi, "A study of the damage of subway structures during the 1995 Hanshin-Awaji earthquake," Cement and Concrete Composites, vol. 19, no. 3, pp. 223-239, 1997.

[5] K. F. Ma, C. T. Lee, Y. B. Tsai, T. C. Shin, and J. Mori, "The Chi-Chi, Taiwan earthquake: large surface displacements on an inland thrust fault," Eos, Transactions American Geophysical Union, Transactions American Geophysical Union, vol. 80, no. 50, pp. 605-620, 1999.

[6] Y. B. Tsai and M. W. Huang, "Strong ground motion characteristics of the chichi, taiwan, earthquake of september 21, 1999," Earthquake Engineering and Engineering Seismology, vol. 2, no. 1, pp. 1-21, 2000.

[7] A. Kurose and P. Berest, Analytical Methods for Dynamic Response of Underground Structures, VI Colloque National AFPS, Palaiseau, France, 2003.

[8] O. Naoto, H. Kiyomi, Y. Takemine et al., "Dynamic behavior of a underground motorway junction due to large earthquake," in Proceedings of the 13th World Conference on Earthquake Engineering, pp. 1215-1223, Vancouver Canada, Augest 2004.

[9] Y. Shen, B. Gao, X. Yang, and S. Tao, "Seismic damage mechanism and dynamic deformation characteristic analysis of mountain tunnel after Wenchuan earthquake," Engineering Geology, vol. 180, pp. 85-98, 2014.

[10] D. Wu, B. Gao, Y. Shen, J. Zhou, and G. Chen, "Damage evolution of tunnel portal during the longitudinal propagation of Rayleigh waves," Natural Hazards, vol. 75, no. 3, pp. 2519-2543, 2015.

[11] H. Xu, T. Li, L. Xia, J. X. Zhao, and D. Wang, "Shaking table tests on seismic measures of a model mountain tunnel," Tunnelling and Underground Space Technology, vol. 60, pp. 197-209, 2016.

[12] X. Q. Fang, J. Q. Lin, X. L. Zhou et al., "Damage evaluation of tunnels in earthquakes," in Proceeding of the 14th World Conference on Earthquake Engineering, pp. 1-9, Beijing China, October 2008.

[13] Y. Jiang, C. Wang, and X. Zhao, "Damage assessment of tunnels caused by the 2004 Mid Niigata Prefecture Earthquake using Hayashi's quantification theory type II," Natural Hazards, vol. 53, no. 3, pp. 425-441, 2010.

[14] Z. Z. Wang and Z. Zhang, "Seismic damage classification and risk assessment of mountain tunnels with a validation for the 2008 Wenchuan earthquake," Soil Dynamics and Earthquake Engineering, vol. 45, no. 1, pp. 45-55, 2013.
[15] W. J. Zang and Z. Z. Wang, "Seismic damage rules and seismic risk of tunnel portals based on fuzzy comprehensive evaluation method," in Proceedings of the Second International Conference on Geotechnical and Earthquake Engineering, pp. 498-506, Chengdu China, October 2013.

[16] J. S. Kim, H. W. Kim, and I. S. Kweon, "A Camera calibration method using concentric circles for vision application," in Proceedings of the 5th Asian Conference on Computer Vision, pp. 1-6, Melbourne Australia, January 2002.

[17] T. L. Saaty, "How to make a decision: the analytic hierarchy process," European Journal of Operational Research, vol. 48, no. 1, pp. 9-26, 1990.

[18] A. Melvin, "Decision-making using the analytic hierarchy process (AHP) and SAS/IML," SESUG, SD-4, pp. 1-12, 2012.

[19] A. Remi, "Numerical discretization of boundary conditions for first order hamilton-jacobi equations," Siam Journal of Numerical Analysis, vol. 41, no. 6, pp. 2233-2261, 2003.

[20] S. T. Li, Spatial Discretization, Los Alamos National Laboratory, Los Alamos, NM, USA, 2007.

[21] M. N. Wang, G. Y. Cui, and G. J. Lin, "Investigation and preliminary analysis on tunnel seismic damage in wenchuan earthquake district," Southwest Highway, vol. 4, pp. 41-46, 2009.

[22] K. Getachew, D. H. Chen, and G. Peng, "Seismic performance evaluation of RC frame designed using Ethiopian and Chinese seismic codes," Advances in Civil Engineering, vol. 2020, Article ID 8493495, , 2020.

[23] 2008 Highway planning, survey, design and research institute of Sichuan provincial department HPSDRISPD, Investigation report of highway earthquake damage in Wenchuan seismic disastrous area. Chengdu, China.

[24] 1997 The professional standards compilation group of people's Republic of China, Deterioration Evaluation standard of railway bridge and tunnel building (DESRBTB). TB/T 2820.12820.8.

[25] J. H. Shin, I. K. Lee, Y. H. Lee, and H. S. Shin, "Lessons from serial tunnel collapses during construction of the Seoul subway Line 5," Tunnelling and Underground Space Technology, vol. 21, no. 3-4, pp. 296-297, 2006.

[26] A. S. Osman, R. J. Mair, and M. D. Bolton, "On the kinematics of 2D tunnel collapse in undrained clay," Géotechnique, vol. 56, no. 9, pp. 585-595, 2006.

[27] H.-S. Shin, Y.-C. Kwon, Y.-S. Jung, G.-J. Bae, and Y.-G. Kim, "Methodology for quantitative hazard assessment for tunnel collapses based on case histories in Korea," International Journal of Rock Mechanics and Mining Sciences, vol. 46, no. 6, pp. 1072-1087, 2009.

[28] T. H. Huang, T. Y. Ho, and C. T. Chang, Quick Investigation and Assessment on Tunnel Structure after Earthquake, and the Relevant Reinforced Methods, Report for Public Construction Commission, Taipei, Taiwan.

[29] C. Qin and S. C. Chian, "2D and 3D stability analysis of tunnel roof collapse in stratified rock: a kinematic approach," International Journal of Rock Mechanics and Mining Sciences, vol. 100, pp. 269-277, 2017.

[30] C. H. Dowding and A. Rozan, "Damage to rock tunnels from earthquake shaking," Journal of the Geotechnical Engineering Division, vol. 104, no. 2, pp. 175-191, 1978.

[31] L. S. Chen, "Report on Highways' Damage in the Wenchuan Earthquake, China Communications Press, Beijing, China, 2012.

[32] H. Wu, H. Lei, and T. Lai, "Shaking table tests for seismic response of orthogonal overlapped tunnel under horizontal 
seismic loading," Advances in Civil Engineering, vol. 2021, Article ID 6633535, , 2021.

[33] Z. Z. Wang, L. Jiang, and Y. Gao, "Shaking table test of seismic response of immersed tunnels under effect of water," Soil Dynamics and Earthquake Engineering, vol. 116, pp. 436-445, 2019.

[34] J. Yu and Z. Z. Wang, "The dynamic interaction of the SoilTunnel-Building system under seismic waves," Soil Dynamics and Earthquake Engineering, vol. 144, Article ID 106686, 2021.

[35] J. S. Xu, H. Xu, R. F. Sun, X. W. Zhao, and Y. Cheng, "Seismic risk evaluation for a planning mountain tunnel using improved analytical hierarchy process based on extension theory," Journal of Mountain Science, vol. 17, no. 1, pp. 244-260, 2020.

[36] Z. F. Fan, J. C. Zhang, H. Xu, and J. Cai, "Transmission of normal P-waves across a single joint based on $g-\lambda$ model," Shock and Vibration, vol. 2019, Article ID 8240586, , 2019.

[37] H. Xu, Z. F. Fan, J. C. Zhang et al., "Transmission and application of a P-wave across joints based on a modified $g-\lambda$ model," International Journal of Rock Mechanics and Mining Sciences, in Press, 2021. 